\title{
Research on AHP-based Youth Preference Way of Three Big Balls Participation in Situational Interest
}

\author{
Xiao Huang ${ }^{1, *}$ and Xiaojuan Wang ${ }^{2}$

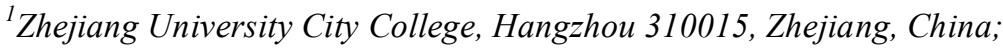 \\ ${ }^{2}$ Department of P.E. Education, Zhejiang University of Technology, China
}

\begin{abstract}
Youth is reserve force of sports development, is main force of Chinese sports further booming development sometime in the future. For Chinese three big balls, youth participation affects its development progress to a certain degree. Research youth preference way in three big balls movements' participation is beneficial to sports teaching according to youth demands and then propel to Chinese three big balls further development. On the basis of studying China's youth main sports ways in participating three big balls, the paper utilizes analytic hierarchy process to make analysis of youth three big balls movements participation's four ways. By comparing combination of sports games and sports, morning exercises or evening exercises, sports competitions, group training four ways' weights, it gets youth participation in three big balls movements preference way that is movement way of combining sports games with sports . Secondly, based on youth situational interest, it carries on further analytic hierarchy process, targeted at story context, language scene, site scene, imagine scene four kinds of movement scenes, combines with youth most preferred sports games and sports combinative way, compares with above movement scenes, finally it puts forward that under movement scene of story context, youth prefer to use sports games and sports combinative way to participate in China three big balls movements.
\end{abstract}

Keywords: Analytic hierarchy process, Sports games, Sports combination, Story context, Sports interests, Three big balls movements.

\section{INTRODUCTION}

China three big balls are foundation of sports development and most important three main sports events in numerous sports events. And youth is the foundation of three big balls development, only do good job in youth three big balls reserve talent then can fundamentally propel to Chinese three big balls development [1].

Pang Jian-Min in the article "Chinese basketball, volleyball, football excellent sports team members numbers dynamic development changes analysis and comparative study", targeted at Chinese three big balls development status, took their excellent athletes numbers changes as main research perspectives, by referencing lots of literatures, researched on its development changes rules. Concluded problems as those Chinese three big balls excellent athletes were dynamically changing, their changing rules would present different features with time passing, researched on the development changes rules would beneficial to propel to Chinese three big balls rapidly growth [2].

Zhao Yu-Ting and others in the article "Chinese excellent athletes and reserve talents exchanging schemes study", they highlighted importance of athletes reserve talents. The paper got first hand information by practical investigation, and made data analysis of information, and then finally got conclusion: Chinese excellent athletes development was emphasis in sports development, and cultivation of reserve talents was the key to it, in order to better strengthen reserve talent strength, it should establish a set of corresponding reserve talent cultivation scheme according to current state Chinese sports development status [3].

Gao Song-Shan in the article "Henan province competitive sports status and reserve talent countermeasures study", took Henan province as main research objects, by researching Chinese sports development status, further analyzed their development features, and highlighted reserve talents importance. The thesis took Henan province sports development as an example, by questionnaire survey, sorting data, finally it got that Henan province development during sports reserve talents cultivation process was not very fast due to techniques, fields and other causes, sports were also not going well, therefore government should put more attentions to sports, advantage was support of reserve talents cultivation [4].

The paper utilizes mathematics analytic hierarchy process, studies Chinese youth participation in three big balls movements preference way under situational interest, and further puts forward Chinese youth preferred three big balls physical exercises ways and corresponding exercises scenes, and then provides theoretical basis for Chinese youth sports development. 


\section{CHINESE YOUTH PARTICIPATION IN THREE BIG BALLS EXERCISES WAYS}

China "three big balls" should put emphasis on excellent athletes' cultivation and focus on reserve talents construction so as to develop rapidly and get rid of present Olympic Games and other competitions states of low level of optimism. Youth is main force of sports development; establish relative complete cultivation system, select excellent athletes for China sports is general progress that competitive sports development should go through.

In recent years, China three big balls development is going well, its position in world sports always not so high. Just in view of athletes, Chinese three big balls international level sports masters are little, most athletes are first level or second level athletes. For youth sports, their exercises ways are main factors that affect youth participation in sports. According to relative investigation, most of world champions are going in for physical exercises since children sports school, and take normative series trainings. Below Table 1 is athletes' development numbers that are classified by events and grades until 2012, data is from China's statistical yearbook data information.

Make statistics of Table $\mathbf{1}$ on above and analyze:

By below (Fig. 1) indication, it can get conclusion: youth most favorite exercise ways are mainly game category and racing category, morning exercise and evening exercise are also youth sports ways. At present, we should establish complete reserve talents cultivation system, encourage youth to participate in sports, positive carry on sports training, and plan a set of feasible talents cultivation scheme. And meanwhile, make full use of universities sports facilities, science and technology resources, as well as universities sports talents, organize university sports team to pave the way for reserve talents cultivation.
Main exercises ways that youth participates in three big balls movements are sports games and sports combination, morning exercise or evening exercise, sports competition, group training. In the four ways, youth preference way is the key to propel to youth to participate in three big balls at present, only adopt youth favorite sports ways to teach then can arouse youth sports enthusiasm and let them to positive join in sports.

\section{Model Establishments}

AHP is based on posed problems' requirements and properties, it divides problem development influential numerous factors into target layer, criterion layer and scheme layer, so that constitutes a hierarchical shape structure, and makes paired mutual comparison of each factor in the same layer, and defines next layer weight with respect to previous layer target. By analyzing every layer, finally rank target layer, criterion layer and scheme layer each factor that the factor importance degree to total target.

Target layer: Youth participation in three big ball movement way of preference.

Criterion layer: Scheme layer influence factors, $C_{1}$ is sports games and sports, $C_{2}$ is morning exercise or evening exercise, $C_{3}$ is sports competition, $C_{4}$ is group training.

Scheme layer: $A_{1}$ is very positive, $A_{2}$ is more positive, $A_{3}$ is general, $A_{4}$ is not too positive

And then it can get (Fig. 2).

\section{Construct Paired Comparison Matrix}

Construct paired comparison matrix is carrying on paired comparison among elements, using matrix to express each layer every element importance to previous layer all elements, here apply operational research expert proposed $1 \sim 9$ ratio scale, as Table 2.
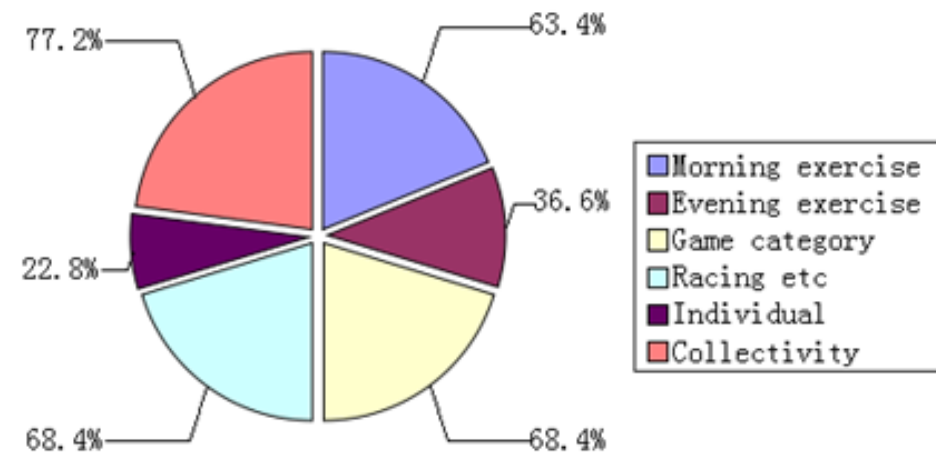

Fig. (1). Sports classification.

Table 1. Exercises ways classification.

\begin{tabular}{|c|c|c|c|c|c|c|}
\hline \multirow{2}{*}{$\begin{array}{c}\text { Exercises ways } \\
\text { classification }\end{array}$} & \multicolumn{2}{|c|}{ Time } & \multicolumn{2}{c|}{ Content } & \multicolumn{2}{c|}{ Form } \\
\cline { 2 - 6 } & Morning exercise & Evening exercise & Game category & Racing category & Individual & Collectivity \\
\hline \hline Percentage $\%$ & $63.4 \%$ & $36.6 \%$ & $68.4 \%$ & $68.4 \%$ & $22.8 \%$ & $77.2 \%$ \\
\hline
\end{tabular}




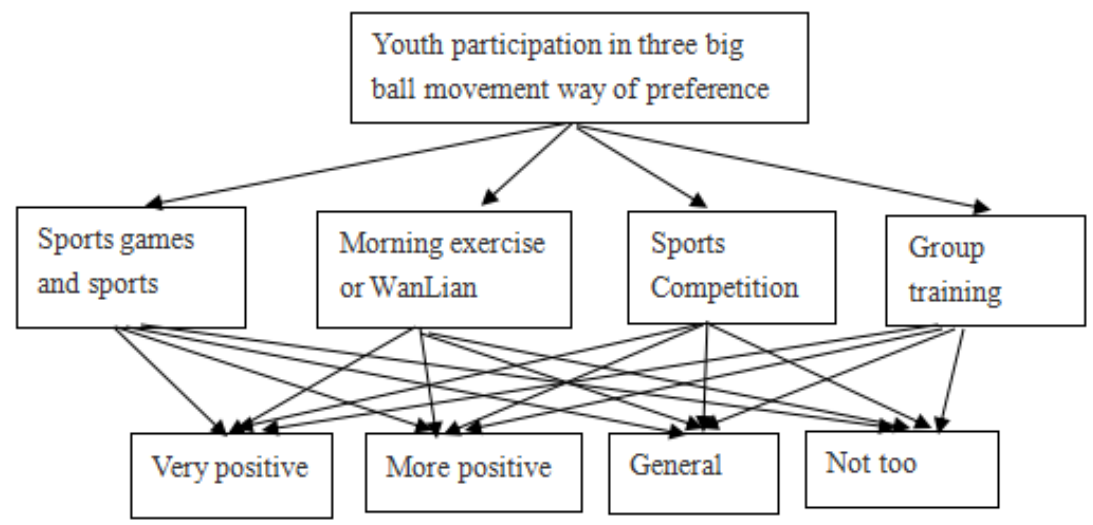

Fig. (2). Hierarchical structural model.

Table 2. 1 9 scale definition.

\begin{tabular}{|c|c|}
\hline Scale $\alpha_{i j}$ & Definition \\
\hline \hline 1 & Factor $\mathrm{i}$ and factor $\mathrm{j}$ have equal importance \\
\hline 3 & Factor $\mathrm{i}$ is slightly more important than factor $\mathrm{j}$ \\
\hline 5 & Factor i is relative more important than factor $\mathrm{j}$ \\
\hline 7 & Factor i is extremely more important than factor $\mathrm{j}$ \\
\hline 9 & Factor $\mathrm{i}$ is absolute more important than factor $\mathrm{j}$ \\
\hline $2,4,6,8$ & Indicates middle state corresponding scale value of above judgments \\
\hline Reciprocal of above each value & If $\mathrm{i}$ factor compares to $\mathrm{j}$ factor, it gets judgment values is, $\alpha_{j i}=1 / \alpha_{j i}, \alpha_{j i}=1$ \\
\hline
\end{tabular}

According to above scale Table 2, set judgment matrix $A$ as:

$$
A=\left(\begin{array}{cccc}
1 & 3 & 3 & 3 \\
\frac{1}{3} & 1 & 5 & 5 \\
\frac{1}{3} & \frac{1}{5} & 1 & 1 \\
\frac{1}{3} & \frac{1}{5} & 1 & 1
\end{array}\right)
$$

Obviously, $A$ is positive reciprocal matrix.

And constructed scheme layer judgment matrixes correspond to different criterion layers are as following Tables 3 and $\mathbf{4}$.

\section{Calculate Compared Element Relative Weight on the Criterion}

(1) Consistency test

Consistency indicator: $C I=\frac{\lambda_{\max }-n}{n-1}$

Random consistency indicator: Randomly generate multiple matrixes, add every matrix consistency indicator and then take average value, it gets RI Table 5 .

Consistency ratio: If $C R=\frac{C I}{R I}<0.1$, constructed paired comparison matrix $\boldsymbol{A}$ passes consistency test.
(2) Calculate weight

For $\boldsymbol{A}$, firstly handling as following:

$$
\begin{aligned}
& \underset{\text { Column vector normalization }}{\longrightarrow}\left(\begin{array}{cccc}
0.866 & 0.945 & 0.5 & 0.5 \\
0.288 & 0.315 & 0.83 & 0.83 \\
0.288 & 0.063 & 0.167 & 0.167 \\
0.288 & 0.063 & 0.167 & 0.167
\end{array}\right) \\
& \stackrel{\text { According to the row sum }}{\longrightarrow}\left(\begin{array}{l}
2.811 \\
2.263 \\
0.685 \\
0.685
\end{array}\right) \stackrel{\text { The normalized }}{\longrightarrow}\left(\begin{array}{l}
0.703 \\
0.566 \\
0.171 \\
0.171
\end{array}\right)=W^{0}
\end{aligned}
$$

And then, by $A \times W^{0}$ it further solves $\lambda^{0}{ }_{\max }=4.246$.

Similarly, criterion layer judgment matrix corresponding maximum feature value and feature vector are successively:

$$
\lambda_{\max }^{1}=3.64, W_{1}=\left(\begin{array}{l}
0.244 \\
0.244 \\
0.512 \\
0.487
\end{array}\right) ; \lambda^{2}{ }_{\max }=3.29, W_{2}=\left(\begin{array}{l}
0.657 \\
0.251 \\
0.092 \\
0.068
\end{array}\right) \text {; }
$$


Table 3. Criterion layer judgment matrix.

\begin{tabular}{|c|c|c|c|c|c|c|c|c|c|}
\hline $\boldsymbol{C}_{\mathbf{1}}$ & $\boldsymbol{A}_{\mathbf{1}}$ & $\boldsymbol{A}_{\mathbf{2}}$ & $\boldsymbol{A}_{\mathbf{3}}$ & $\boldsymbol{A}_{\mathbf{4}}$ & $\boldsymbol{C}_{\mathbf{2}}$ & $\boldsymbol{A}_{\mathbf{1}}$ & $\boldsymbol{A}_{\mathbf{2}}$ & $\boldsymbol{A}_{\mathbf{3}}$ & $\boldsymbol{A}_{\mathbf{4}}$ \\
\hline \hline$A_{1}$ & 1 & 2 & 3 & 5 & $A_{1}$ & 1 & 2 & 3 \\
\hline$A_{2}$ & $1 / 2$ & 1 & $1 / 3$ & 3 & $A_{2}$ & $1 / 2$ & 1 & $1 / 3$ \\
\hline$A_{3}$ & $1 / 3$ & 3 & 1 & 2 & $A_{3}$ & $1 / 3$ & 3 & 1 & 2 \\
\hline$A_{4}$ & $1 / 5$ & $1 / 3$ & $1 / 2$ & 1 & $A_{4}$ & $1 / 3$ & $1 / 3$ & $1 / 2$ \\
\hline
\end{tabular}

Table 4. Criterion layer judgment matrix.

\begin{tabular}{|c|c|c|c|c|c|c|c|c|c|}
\hline $\boldsymbol{C}_{\mathbf{3}}$ & $\boldsymbol{A}_{\mathbf{1}}$ & $\boldsymbol{A}_{\mathbf{2}}$ & $\boldsymbol{A}_{\mathbf{3}}$ & $\boldsymbol{A}_{\mathbf{4}}$ & $\boldsymbol{C}_{\mathbf{4}}$ & $\boldsymbol{A}_{\mathbf{1}}$ & $\boldsymbol{A}_{\mathbf{2}}$ & $\boldsymbol{A}_{\mathbf{3}}$ & $\boldsymbol{A}_{\mathbf{4}}$ \\
\hline \hline$A_{1}$ & 1 & 3 & 3 & 5 & $A_{1}$ & 1 & 2 & 3 \\
\hline$A_{2}$ & $1 / 3$ & 1 & 2 & 3 & $A_{2}$ & $1 / 2$ & 1 & $1 / 3$ \\
\hline$A_{3}$ & $1 / 3$ & $1 / 2$ & 1 & 2 & $A_{3}$ & $1 / 3$ & 3 & 1 \\
\hline$A_{4}$ & $1 / 5$ & $1 / 3$ & $1 / 2$ & 1 & $A_{4}$ & $1 / 2$ & $1 / 4$ & $1 / 2$ & 1 \\
\hline
\end{tabular}

Table 5. Random consistency indicator.

\begin{tabular}{|c|c|c|c|c|c|c|c|c|c|c|c|}
\hline$n$ & 1 & 2 & 3 & 4 & 5 & 6 & 7 & 8 & 9 & 10 & 11 \\
\hline$R I$ & 0 & 0 & 0.58 & 0.90 & 1.12 & 1.24 & 1.32 & 1.41 & 1.45 & 1.49 & 1.51 \\
\hline
\end{tabular}

$\lambda_{\text {max }}^{3}=3.31, W_{1}=\left(\begin{array}{l}0.648 \\ 0.204 \\ 0.148 \\ 0.136\end{array}\right) ; \lambda_{\max }^{4}=3.31, W_{4}=\left(\begin{array}{l}0.648 \\ 0.204 \\ 0.148 \\ 0.125\end{array}\right)$

By calculation, it can get paired comparison matrix $\boldsymbol{A}$ maximum feature value $\lambda_{\max }=4.246, R I=0.90$

By consistency indicator $C I=\frac{\lambda_{\max }-n}{n-1}$, input data, it can calculate and get $C I=\frac{4.242-4}{4-1}=0.081$

And by consistency ratio $C R=\frac{C I}{R I}=\frac{0.081}{0.90}=0.089<0.1$, so constructed paired comparison matrix $\boldsymbol{A}$ passes consistency test. Similarly, it can verify criterion layer judgment matrixes also pass consistency test.

(3) Calculate combination weight vector

By $W^{1}=\left(w_{1}, w_{2}, w_{3}, w_{4}\right)$, and $W=W^{l} \times W^{0}$ it can calculate and get

$$
W=\left(\begin{array}{l}
0.553 \\
0.308 \\
0.104 \\
0.035
\end{array}\right)
$$

\section{Analyze Results}

By above combination weight calculation result, it can analyze that in studying of youth participation in three big balls preference way, there are $55.3 \%$ youth very like sports games and sports combinative exercise way, the ones that relative like morning exercise or evening exercise way occupy $30.8 \%$, the ones show general attitude towards sports race way occupy $10.4 \%$, only $3.5 \%$ youth don't like group training way so much. It also proves sports games and sports combinative exercise way is contemporary youth favorite three big balls movement way.

\section{Youth Participation in Three Big Balls Movement Situational Interest Study}

Usually, youth participation in three big balls movement way will also suffer situational interest influence. Situational interest will affect youth participation in sports positivity, in general it mainly has story context, language scene, site scene and imagine the scene four kinds. With respect to this, on the basis of above analytic hierarchy process, it further studies youth participation in three big balls movement situational interest, and then gets youth favorite exercise scene.

Target layer: The most popular scene with the youth sports

Criterion layer: Scheme layer influence factors, $C_{1}$ is story context, $C_{2}$ is language scene, $C_{3}$ is site scene, $C_{4}$ is imagine the scene.

Scheme layer: $A_{1}$ is like very much, $A_{2}$ is like better, $A_{3}$ is general, $A_{4}$ is not like too much

And then it can get (Fig. 3). 


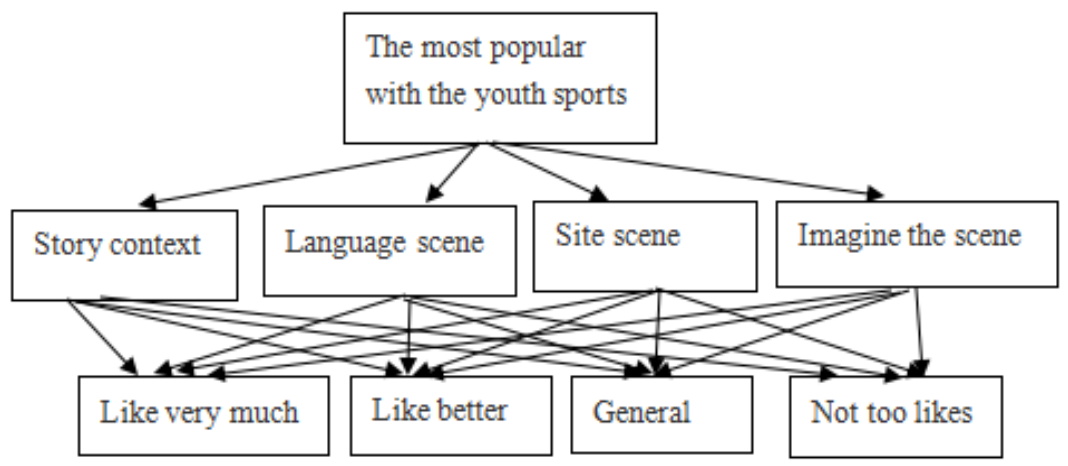

Fig. (3). Hierarchical structural model.

Table 6. Criterion layer judgment matrix.

\begin{tabular}{|c|c|c|c|c|c|c|c|c|c|}
\hline $\boldsymbol{C}_{\boldsymbol{I}}$ & $\boldsymbol{A}_{\mathbf{1}}$ & $\boldsymbol{A}_{\mathbf{2}}$ & $\boldsymbol{A}_{\mathbf{3}}$ & $\boldsymbol{A}_{\mathbf{4}}$ & $\boldsymbol{C}_{\mathbf{2}}$ & $\boldsymbol{A}_{\mathbf{1}}$ & $\boldsymbol{A}_{\mathbf{2}}$ & $\boldsymbol{A}_{\mathbf{3}}$ & $\boldsymbol{A}_{\mathbf{4}}$ \\
\hline \hline$A_{1}$ & 1 & 3 & 4 & 5 & $A_{2}$ & 1 & 2 & 4 \\
\hline$A_{2}$ & $1 / 3$ & 1 & $1 / 3$ & 3 & $A_{3}$ & $1 / 2$ & 1 & $1 / 3$ \\
\hline$A_{3}$ & $1 / 4$ & 3 & 1 & 2 & $A_{4}$ & $1 / 4$ & 3 & 1 \\
\hline$A_{4}$ & $1 / 5$ & $1 / 3$ & $1 / 2$ & 1 & $A_{4}$ & $1 / 3$ & $1 / 3$ & $1 / 2$ & 1 \\
\hline
\end{tabular}

\section{Construct Paired Comparison Matrix}

By 2.3 scale table, it can get judgment matrix as $A$ is:

$$
A=\left(\begin{array}{cccc}
1 & 3 & 4 & 2 \\
\frac{1}{3} & 1 & 3 & 5 \\
\frac{1}{4} & \frac{1}{3} & 1 & 1 \\
\frac{1}{2} & \frac{1}{5} & 1 & 1
\end{array}\right)
$$

And constructed scheme layer judgment matrixes correspond to different criterion layers are as shown in Tables 6 and 7.

\section{Calculate Compared Element Relative Weight on the Criterion}

By calculation, it can test all above judgment matrixes pass consistency test. And to $\boldsymbol{A}$, it carries on following handling:

$$
\begin{aligned}
& \stackrel{\text { Column vector normalization }}{\longrightarrow}\left(\begin{array}{llll}
0.866 & 0.945 & 0.510 & 0.425 \\
0.234 & 0.325 & 0.857 & 0.732 \\
0.282 & 0.053 & 0.124 & 0.157 \\
0.188 & 0.163 & 0.167 & 0.128
\end{array}\right) \\
& \stackrel{\text { According to the row sum }}{\longrightarrow}\left(\begin{array}{l}
2.921 \\
2.253 \\
0.622 \\
0.615
\end{array}\right) \stackrel{\text { The normalized }}{\longrightarrow}\left(\begin{array}{l}
0.698 \\
0.575 \\
0.512 \\
0.435
\end{array}\right)=W^{0}
\end{aligned}
$$

And then get: $\lambda^{0}{ }_{\max }=4.225, W_{1}=\left(\begin{array}{l}0.698 \\ 0.575 \\ 0.512 \\ 0.435\end{array}\right)$
Similarly, criterion layer judgment matrix corresponding maximum feature value and feature vector are successively:

$$
\lambda_{\text {max }}^{1}=3.57, W_{1}=\left(\begin{array}{l}
0.232 \\
0.218 \\
0.114 \\
0.587
\end{array}\right) ; \lambda^{2}{ }_{\max }=3.01, W_{2}=\left(\begin{array}{c}
0.623 \\
0.245 \\
0.193 \\
0.157
\end{array}\right)
$$

$\lambda_{\text {max }}^{3}=3.05, W_{1}=\left(\begin{array}{l}0.655 \\ 0.232 \\ 0.157 \\ 0.145\end{array}\right) ; \lambda_{\max }^{4}=3.29, W_{4}=\left(\begin{array}{l}0.624 \\ 0.258 \\ 0.144 \\ 0.119\end{array}\right)$

By $W^{1}=\left(w_{1}, w_{2}, w_{3}, w_{4}\right)$, and $W=W^{l} \times W^{0}$, it can calculate and get:

$W=\left(\begin{array}{l}0.565 \\ 0.321 \\ 0.101 \\ 0.013\end{array}\right)$

By above weight comparison, it is clear that in four kinds of scenes, story context is most well-received by youth, its proportion is $56.5 \%$, language scene is preferred by $32.1 \%$ youth, other two kinds of ways proportions are relatively little. It shows in sports games and sports combinative three big balls movement way, adopt story context situational teaching way can better arouse youth enthusiasm of participating in three big balls movement. 
Table 7. Criterion layer judgment matrix.

\begin{tabular}{|c|c|c|c|c|c|c|c|c|c|}
\hline $\boldsymbol{C}_{\mathbf{3}}$ & $\boldsymbol{A}_{\mathbf{1}}$ & $\boldsymbol{A}_{\mathbf{2}}$ & $\boldsymbol{A}_{\mathbf{3}}$ & $\boldsymbol{A}_{\mathbf{4}}$ & $\boldsymbol{C}_{\mathbf{4}}$ & $\boldsymbol{A}_{\mathbf{1}}$ & $\boldsymbol{A}_{\mathbf{2}}$ & $\boldsymbol{A}_{\mathbf{3}}$ & $\boldsymbol{A}_{\mathbf{4}}$ \\
\hline \hline$A_{1}$ & 1 & 3 & 4 & 5 & $A_{1}$ & 1 & 2 & 3 \\
\hline$A_{2}$ & $1 / 3$ & 1 & 2 & 4 & $A_{2}$ & $1 / 2$ & 1 & $1 / 2$ \\
\hline$A_{3}$ & $1 / 4$ & $1 / 2$ & 1 & 2 & $A_{3}$ & $1 / 3$ & 2 & 1 \\
\hline$A_{4}$ & $1 / 5$ & $1 / 4$ & $1 / 2$ & 1 & $A_{4}$ & $1 / 5$ & $1 / 3$ & $1 / 2$ & 1 \\
\hline
\end{tabular}

\section{CONCLUSION}

The paper firstly analyzes Chinese youth participation in three big balls exercises ways, and on this basis, utilizes analytic hierarchy process, make analysis of youth three big balls movements participation's combination of sports games and sports, morning exercises or evening exercises, sports competitions, group training four ways, it gets combination of sports games and sports is youth most preferred way when participate in three big balls movement.

On the basis of studying youth participation in three big balls movement preference way, it further carries on sports situational analysis. Targeted at story context, language scene, site scene, imagine scene four kinds of movement scenes, utilize analytic hierarchy process, compare final weights, and then get story context is most well-received movement scene by youth, when youth participates in three big balls movement, they preferred to movement way of combining sports games with sports, and is inclined to story context situational teaching way.

\section{CONFLICT OF INTEREST}

The authors confirm that this article content has no conflict of interest.

\section{ACKNOWLEDGEMENTS}

Declared none.

\section{REFERENCES}

[1] C. Liu, and B. Guan, "Power of harmony-against the background of chinese culture," Journal of Tianjin University(Social Sciences), vol. 11, no. 5, pp. 453-457, 2009.

[2] J. Lu, "The two states of tao and the two forms of object," Journal of Anhui University (Philosophy \& Social Sciences), vol. 30, no. 6, pp. 5-6, 2006.

[3] X. Wang, "Thoughts and analyses of the construction of harmonious enterprises in China," Research On Development, vol. 22, no. 5, pp. 57-60, 2007.

[4] X. Xu, "Reflections on the modern value of the ideas of Lao Zi," Journal of Anhui University(Philosophy \& Social Sciences), vol. 30, no. 6, pp. 6-8, 2006. 